Bull. Mater. Sci., Vol. 18, No. 5, September 1995, pp. 623-630. (C) Printed in India.

RAPID COMMUNICATION

\title{
A critical assessment of the standard molar Gibbs free energy of formation of $\mathrm{NiWO}_{4}$
}

\author{
P MARKONDEYA RAJ \\ Department of Metallurgy, Indian Institute of Science, Bangalore 560012, India \\ MS received 24 July 1995
}

\begin{abstract}
Three independent studies have been reported on the free energy of formation of $\mathrm{NiWO}_{4}$. Results of these measurements are analyzed by the "third-law" method, using thermal functions for $\mathrm{NiWO}_{4}$ derived from both low and high temperature heat capacity measurements. Values for the standard molar enthalpy of formation of $\mathrm{NiWO}_{4}$ at $298 \cdot 15 \mathrm{~K}$ obtained from "third-law" analysis are compared with direct calorimetric determinations. Only one set of free energy measurements is found to be compatible with calorimetric enthalpies of formation. The selected value for $\Delta_{\mathrm{f}} \mathrm{H}_{\mathrm{m}}^{0}\left(\mathrm{NiWO}_{4}, \mathrm{cr}, 298.15 \mathrm{~K}\right)$ is the average of the three calorimetric measurements, using both high temperature solution and combustion techniques, and the compatible free energy determination. A new set of evaluated data for $\mathrm{NiWO}_{4}$ is presented.
\end{abstract}

Keywords. "Third-law" analysis; Gibbs energy function; e.m.f. measurements; enthalpy of formation; heat capacity; entropy; phase relations.

\section{Introduction}

Tungsten-fibre reinforced composites with nickel or nickel base alloy as a matrix material find application as a structural component under extreme conditions such as those encountered in turbo-jet engines. Studies on the high-temperature stability of nickel-coated composites in atmospheres containing oxygen indicate that the internal oxidation of tungsten result in a mixture of several binary oxides and $\mathrm{NiWO}_{4}$ (Kvernes and Kofstad 1973). Oxidation behaviour of the composite depends upon the relative stability of phases that appear during its oxidation. Conversely, thermodynamic properties of various phases in the system $\mathrm{Ni}-\mathrm{W}-\mathrm{O}$ also guide the reduction path of $\mathrm{NiWO}_{4}$. Studies on the reduction kinetics of complex oxides are essential in developing processes for the synthesis of various composites through powder metallurgy routes.

Recently, Aune et al (1994) reported values for the standard Gibbs free energy of formation of $\mathrm{NiWO}_{4}$ in the temperature range $1167 \mathrm{~K}$ to $1317 \mathrm{~K}$ using a solid-state galvanic cell incorporating calcia-stabilized zirconia as the electrolyte. Their results, after correcting for obvious errors, differ significantly from earlier measurements of the free energy of formation by Jacob (1977) and Rezukhina and Kashina (1974). At a temperature of $1200 \mathrm{~K}$ the results of Rezukhina and Kashina (1974) are more negative by $\sim 41.4 \mathrm{~kJ} \mathrm{~mol}^{-1}$ than those reported by Aune et al (1994).

The heat capacity of $\mathrm{NiWO}_{4}$ has been measured from $5 \mathrm{~K}$ to $350 \mathrm{~K}$ by Landee and Westrum (1976) using an adiabatic calorimeter. There is a cooperative transition from antiferromagnetically-ordered state to the paramagnetic state at $59.8 \mathrm{~K}$. The excess entropy associated with this antiferromagnetic anomaly was evaluated as $R \ln 3$ for $\mathrm{NiWO}_{4}$. The standard entropy of $\mathrm{NiWO}_{4}$ at $298 \cdot 15 \mathrm{~K}$ obtained by integrating the low temperature heat capacities is $(119 \cdot 34 \pm 0 \cdot 42) \mathrm{J} \mathrm{mol}^{-1} \mathrm{~K}^{-1}$. Enthalpy increments $\left(H_{\mathrm{m}}^{0}(T)-H_{\mathrm{m}}^{0}(298 \cdot 15 \mathrm{~K})\right)$ have been measured by Rezukhina and Zharkova (1958) for 


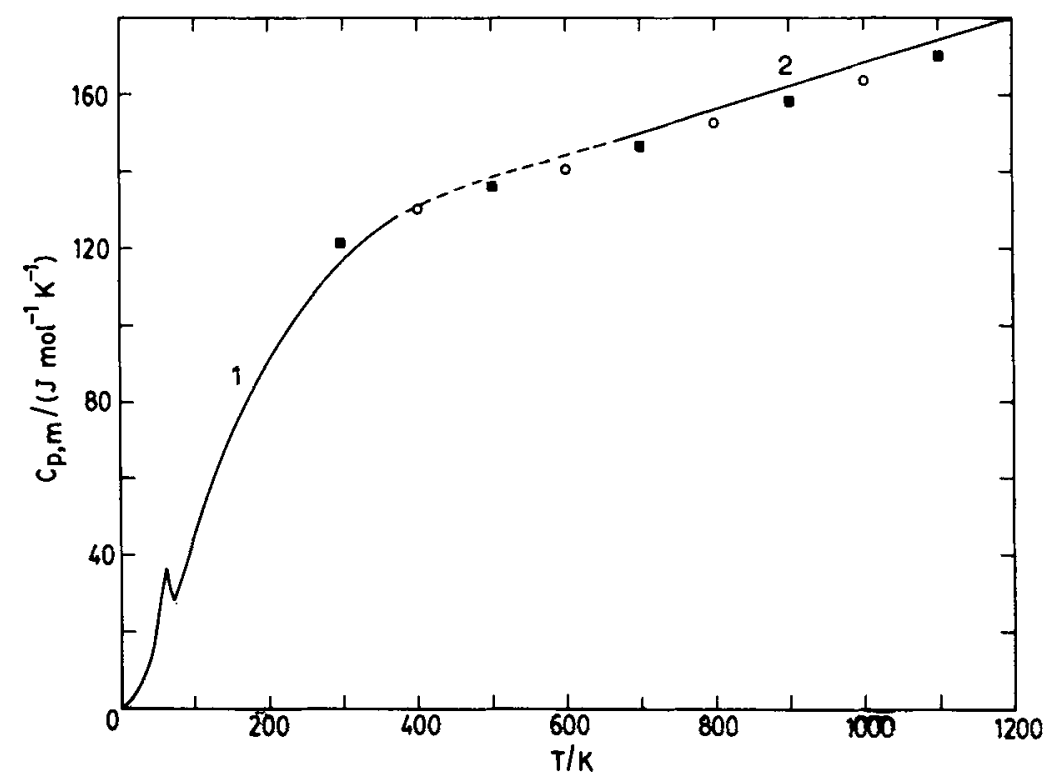

Figure 1. Temperature dependence of molar heat capacity of $\mathrm{NiWO}_{4}$. (1) Low temperature measurements of Landee and Westrum (1976); (2) high temperature measurements of Zharkova and Rezukhina (1958); $\mathbf{n}$, Values suggested in the compilation of Mah and Pankratz (1976); O, Data given in the compilations of Knacke et al (1991).

four temperatures ranging from $715 \mathrm{~K}$ to $1107 \mathrm{~K}$. The samples were dropped from high temperatures into a calorimeter maintained at room temperature. From these measurements the high temperature heat capacity can be deduced:

$$
C_{\mathrm{p}, \mathrm{m}}^{0}=102+0.0657(T / \mathrm{K}) \mathrm{J} /(\mathrm{mol} \mathrm{K}) \text {. }
$$

As shown in figure 1, the heat capacity from low temperature studies joins reasonably well with that from high temperature measurements.

The enthalpy of formation, $\Delta_{\mathrm{f}} \mathrm{H}_{\mathrm{m}}^{0}\left(\mathrm{NiWO}_{4}, \mathrm{cr}, 298 \cdot 15 \mathrm{~K}\right)$, has been measured calorimetrically by three groups of investigators. Navrotsky and Kleppa (1969) used hightemperature solution calorimetry, with $3 \mathrm{Na}_{2} \mathrm{O} \cdot 4 \mathrm{MoO}_{3}$ as the solvent, to obtain a value of $(-44.1 \pm 1 \cdot 2) \mathrm{kJ} \mathrm{mol}^{-1}$ for the enthalpy of formation of $\mathrm{NiWO}_{4}$ from $\mathrm{NiO}$ and $\mathrm{WO}_{3}$ at $970 \mathrm{~K}$. Amosse and Mathieu (1974) determined the enthalpy of formation of $\mathrm{NiWO}_{4}$ from component oxides as $(-49 \cdot 8 \pm 1 \cdot 7) \mathrm{kJ} \mathrm{mol}^{-1}$ at $298 \cdot 15 \mathrm{~K}$. In separate experiments, they measured the enthalpy changes associated with the solution of $\mathrm{NiWO}_{4}$ and an equimolar mixture of $\mathrm{WO}_{3}$ and $\mathrm{NiO}$ at $298.15 \mathrm{~K}$ in a metaborate $\left(0.5 \mathrm{LiBO}_{2}-0.5 \mathrm{NaBO}_{2}\right)$ solvent maintained at $940 \mathrm{~K}$. Porshina and Rezukhina (1960) used a bomb calorimeter to determine the $\Delta_{\mathrm{f}} H_{\mathrm{m}}^{0}\left(\mathrm{NiWO}_{4}, \mathrm{cr}, 298 \cdot 15 \mathrm{~K}\right)=$ $(-1133.86 \pm 3.35) \mathrm{kJ} \mathrm{mol}^{-1}$. This corresponds to an enthalpy of formation of $(-51 \cdot 1 \pm 4) \mathrm{kJ} \mathrm{mol}^{-1}$ from component oxides, $\mathrm{NiO}$ and $\mathrm{WO}_{3}$. In this deduction, the enthalpies of formations of binary oxides were taken from Pankratz (1982). The three sets of calorimetric measurements on enthalpy of formation of $\mathrm{NiWO}_{4}$ are in fair agreement.

With the data now available it is possible to critically analyze the three independent high-temperature measurements of the $\Delta_{\mathrm{f}} G_{\mathrm{m}}^{0}\left(\mathrm{NiWO}_{4}, \mathrm{cr}\right)$. Aune et al (1994) did not 
compare their results with the calorimetric data. Thermodynamic data of $\mathrm{NiWO}_{4}$ have been reported in the compilations of Mah and Pankratz(1976) and Knacke et al (1991). However, these assessments did not take into account all the information now available in the literature. For example, both compilations use estimated values for the standard entropy of $\mathrm{NiWO}_{4}$.

\section{Analysis and discussion}

\subsection{Free energy data of Aune et al (1994) - correction of error}

Aune et al (1994) measured the standard molar Gibbs free energy of formation of $\mathrm{NiWO}_{4}$ in the temperature range $1167 \mathrm{~K}$ to $1318 \mathrm{~K}$ using a solid-state galvanic cell:

$$
{ }^{(-)} \mathrm{Pt}\left|\underline{\mathrm{Ni}}(\mathrm{s}), \mathrm{NiWO}_{4}(\mathrm{~s}), \mathrm{WO}_{2 \cdot 72}(\mathrm{~s})\right|(1-x) \mathrm{ZrO}+x \mathrm{CaO}|\mathrm{NiO}(\mathrm{s}), \mathrm{Ni}(\mathrm{s})| \mathrm{Pt}^{(+)},
$$

where $\underline{\mathrm{Ni}}$ (s) denotes the $\mathrm{Ni}$-rich f.c.c alloy containing a small amount $\left(X_{\mathrm{W}}<0.03\right)$ of tungsten. The virtual cell reaction was represented as:

$$
1 \cdot 28 \mathrm{NiO}(\mathrm{s})+\underline{\mathrm{Ni}}(\mathrm{s})+\mathrm{WO}_{2 \cdot 72}=\mathrm{NiWO}_{4}+1 \cdot 28 \mathrm{Ni}(\mathrm{s}) \text {. }
$$

From the e.m.f.s measured by Aune et al (1994) the standard free energy for the cell reaction can be obtained:

$$
\Delta_{2} G_{\mathrm{m}}^{0}=-14.610-0.02046(T / \mathrm{K}) \mathrm{kJ} / \mathrm{mol} \text {. }
$$

Combining with standard free energies of formation of $\mathrm{NiO}$ (Charette and Flengas 1968 ) and $\mathrm{WO}_{2 \cdot 72}$ (Rizzo et al 1969) and ignoring the small correction for the activity of $\mathrm{Ni}$ in the alloy, the free energy for the formation of $\mathrm{NiWO}_{4}$ is obtained. For the reaction,

$$
\begin{aligned}
& \mathrm{Ni}(\mathrm{s})+\mathrm{W}(\mathrm{s})+2 \mathrm{O}_{2}(\mathrm{~g})=\mathrm{NiWO}_{4}(\mathrm{~s}) \\
& \Delta_{4} G_{\mathrm{m}}^{\mathrm{o}}=-1067 \cdot 890+0 \cdot 3033(T / \mathrm{K}) \mathrm{kJ} / \mathrm{mol} .
\end{aligned}
$$

The auxiliary data for $\mathrm{NiO}$ and $\mathrm{WO}_{2.72}$ used here are identical with those employed by Aune et al (1994). They have incorrectly calculated

$$
\Delta_{4} G_{\mathrm{m}}^{0}=-1092 \cdot 4+0 \cdot 310(T / \mathrm{K}) \mathrm{kJ} / \mathrm{mol},
$$

which is more negative by $\sim 16.5 \mathrm{~kJ} \mathrm{~mol}^{-1}$ at $1200 \mathrm{~K}$. This error in their calculation is also reflected in figure 3 of their paper. The correction for the reduced activity of the nickel in the solid solution, estimated assuming Raoult's law for the solvent is $0.3 \mathrm{~kJ} \mathrm{~mol}^{-1}$ at $1200 \mathrm{~K}$. However, since the composition of the solid solution has not been experimentally determined, and the value calculated by Aune et al (1994) is dependent on their value for Gibbs free energy of formation of $\mathrm{NiWO}_{4}$, the justification for this small correction is at best tenuous.

\subsection{Computation of Gibbs energy function $(\mathrm{GEF})$ for $\mathrm{NiWO}_{4}$}

From the high temperature heat capacity reported by Rezukhina and Zharkova (1958), $\left(H_{\mathrm{m}}^{0}(T)-H_{\mathrm{m}}^{0}(298 \cdot 15 \mathrm{~K})\right)$ and $\left(S_{\mathrm{m}}^{0}(T)-S_{\mathrm{m}}^{0}(298 \cdot 15 \mathrm{~K})\right)$ have been calculated. Using the value of the entropy at $298 \cdot 15 \mathrm{~K}$, reported by Landee and Westrum (1976) from low temperature heat capacity studies, values of $S_{\mathrm{m}}^{0}(T)$ have been derived. 


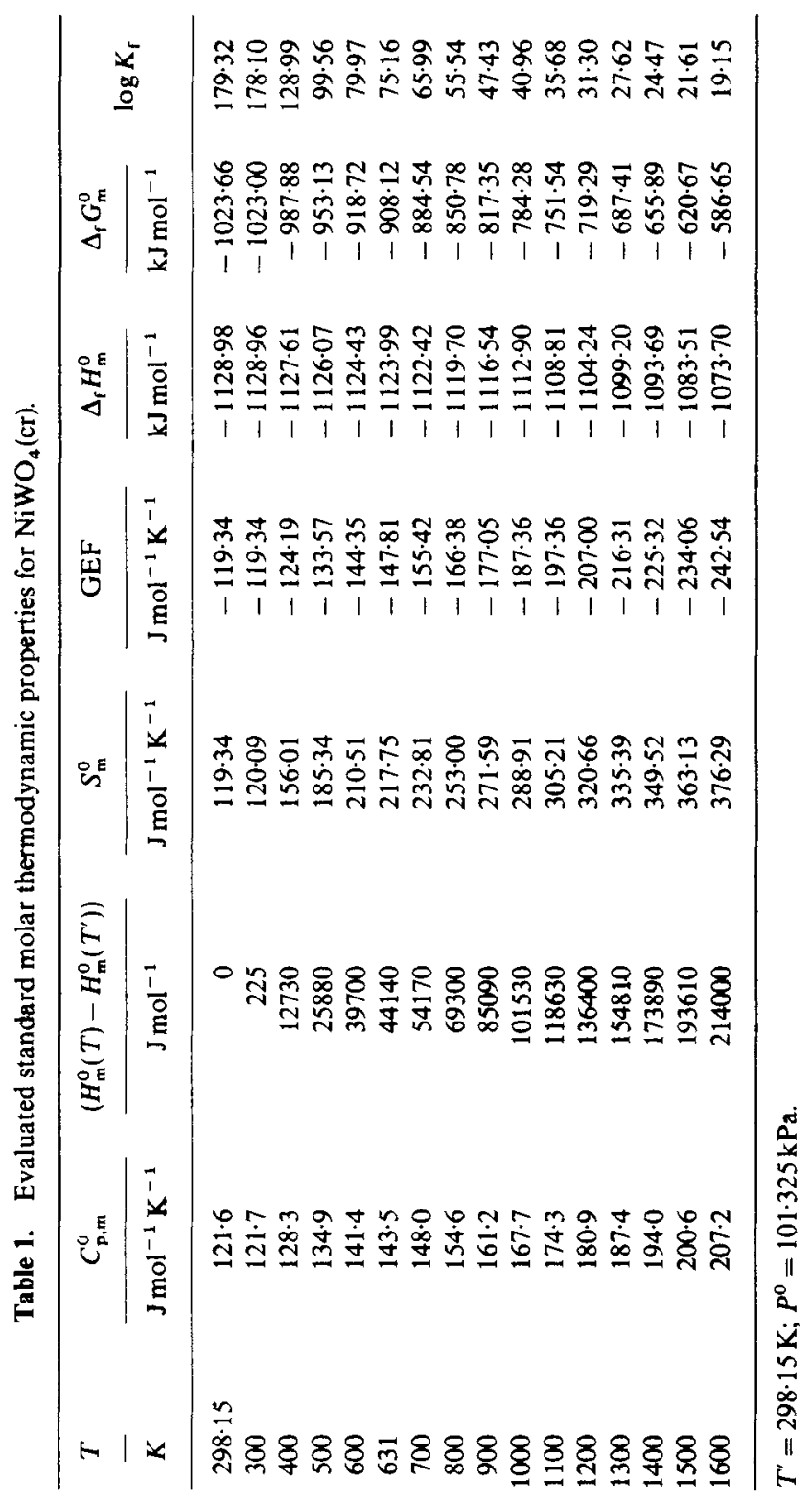


The Gibbs energy function, defined as,

$$
\mathrm{GEF}=-S_{\mathrm{m}}^{0}+\frac{H_{\mathrm{m}}^{0}(T)-H_{\mathrm{m}}^{0}(298 \cdot 15 \mathrm{~K})}{T},
$$

and calculated as a function of temperature, is summarized in table 1.

\section{3 'Third-law' analysis of the high temperature free energy data}

The corrected expression (5) for the energy of formation of $\mathrm{NiWO}_{4}$ calculated from the e.m.f. measurements of Aune et al (1994), is significantly different from that given by Rezukhina and Kashina (1974):

$$
\Delta_{4} G_{\mathrm{m}}^{0}=-1108 \cdot 51+0 \cdot 302(T / \mathrm{K}) \mathrm{kJ} / \mathrm{mol},
$$

in the temperature range $1150 \mathrm{~K}$ to $1350 \mathrm{~K}$, and that given by Jacob(1977):

$$
\Delta_{4} G_{\mathrm{m}}^{0}=-1104 \cdot 7+0.323(T / \mathrm{K}) \mathrm{kJ} / \mathrm{mol},
$$

in the temperature range $1025 \mathrm{~K}$ to $1300 \mathrm{~K}$. The galvanic cell employed by Jacob (1977) was identical to that used by Aune et al (1994). The e.m.f.s obtained by Aune et al (1994) are significantly lower than that registered by Jacob (1977). At a temperature of $1200 \mathrm{~K}$, the difference is $25 \mathrm{mV}$. Rezukhina and Kashina (1974) did their studies on the cell,

$$
\mathrm{Fe}_{0.947} \mathrm{O}, \mathrm{Fe}\left|\left(\mathrm{ZrO}_{2}\right)_{0.85}(\mathrm{CaO})_{0.15}\right| \mathrm{NiWO}_{4}, \mathrm{WO}_{2}(\mathrm{~s}),(\mathrm{Ni}-\mathrm{W})_{\text {soln }} \text {. }
$$

In the temperature range $1170 \mathrm{~K}$ to $1243 \mathrm{~K}$, the alloy in equilibrium with $\mathrm{NiWO}_{4}$ and $\mathrm{WO}_{2}$ was assumed to have the composition $\mathrm{Ni}_{4} \mathrm{~W}$. From $1243 \mathrm{~K}$ to $1346 \mathrm{~K}$, composition in the alloy was considered as $\mathrm{Ni}_{0.83} \mathrm{~W}_{0.17}$. There are important differences among the three high temperature studies in the composition of the tungsten oxide phase in equilibrium with $\mathrm{NiWO}_{4}$ and Ni-rich alloy. Rezukhina and Kashina (1974) identify $\mathrm{WO}_{2}$ as the oxide phase in equilibrium in the entire range of temperatures covered in their study. Jacob (1977) identified the phase as $\mathrm{WO}_{2.72}$ by X-ray diffraction. Aune et al (1994) suggest $\mathrm{WO}_{2.72}$ as oxide phase in equilibrium above $1167 \mathrm{~K}$ and $\mathrm{WO}_{2.9}$ at lower temperatures. The inference regarding the change in oxide composition was based on the observed change in the slope of e.m.f. as a function of temperature. They could not get unambiguous X-ray evidence for the change in the composition of the oxide phase. Careful phase diagram studies are required to solve this discrepancy.

Measurements on metastable equilibria can also be used to derive thermodynamic information on one of the phases involved (Jacob and Srikanth 1988). E.m.f. studies of ternary oxides at moderate temperatures can sometime yield the correct values even when they are mixed with other phases not in true thermodynamic equilibrium. Therefore, it is prudent to consider all the e.m.f. studies on $\mathrm{NiWO}_{4}$ for the 'third-law' analysis.

The validity of the expressions for the free energy of formation of $\mathrm{NiWO}_{4}$ can be checked by the 'third-law' analysis. The standard enthalpy of formation, $\Delta_{\mathrm{f}} H_{\mathrm{m}}^{0}$ $\left(\mathrm{NiWO}_{4}, \mathrm{cr}, 298.15 \mathrm{~K}\right)$ can be calculated from each value of $\Delta_{\mathrm{f}} G_{\mathrm{m}}^{\mathrm{o}}\left(\mathrm{NiWO}_{4}, \mathrm{cr}\right)$ at temperature $T$ and the Gibbs energy function (GEF), for the reaction (4):

$$
\Delta_{\mathrm{f}} H_{\mathrm{m}}^{0}(298 \cdot 15 \mathrm{~K})=-T \Delta(\mathrm{GEF})+\Delta_{\mathrm{f}} G_{\mathrm{m}}^{0}(T) .
$$




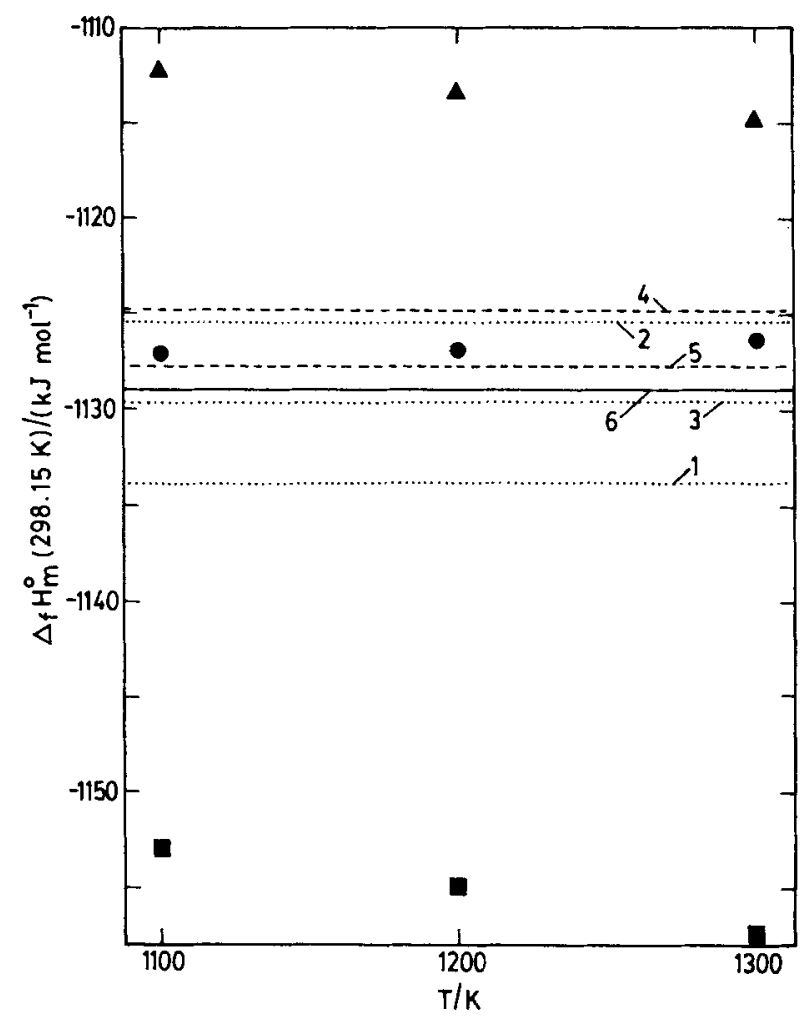

Figure 2. Comparison of standard molar enthalpy of formation of $\mathrm{NiWO}_{4}$ at $298 \cdot 15 \mathrm{~K}$. Results of 'third-law' analysis: $\square$, Rezukhina and Kashina (1974); - Jacob (1977); $\triangle$, Aune et al (1994). Calorimetric data: (1) Porshina and Rezukhina (1960), (2) Navrotsky and Kleppa (1969), (3) Amosse and Mathieu (1974). Data from compilations: (4) Mah and Pankratz (1976), (5) Knacke $e t$ al (1991). The value selected in this evaluation is indicated by line 6 .

The values of GEF for $\mathrm{Ni}, \mathrm{W}$ and $\mathrm{O}_{2}$ are taken from the compilations by Pankratz (1982) and GEF for $\mathrm{NiWO}_{4}$ evaluated in this work is used. The values for $\Delta_{\mathrm{f}} H_{\mathrm{m}}^{0}\left(\mathrm{NiWO}_{4}, \mathrm{cr}, 298 \cdot 15 \mathrm{~K}\right)$, evaluated from the free energy data at 1100,1200 and $1300 \mathrm{~K}$ are compared with the calorimetric data in figure 2 .

It can be seen that the values of $\Delta_{\mathrm{f}} \mathrm{H}_{\mathrm{m}}^{\mathrm{o}}\left(\mathrm{NiWO}_{4}, \mathrm{cr}, 298.15 \mathrm{~K}\right)$ obtained from the 'third-law' analysis of the free energy data of Jacob (1977) are relatively constant and in fair agreement with calorimetric values reported in the literature. The free energies of formation of $\mathrm{NiWO}_{4}$ given by Aune et al (1994) and Rezukhina and Kashina (1974) are not consistent with the calorimetric data. Moreover, the analysis of these results show a small but significant systematic drift in the enthalpy of formation. This may be indicative of small temperature dependent errors in their measurements.

\subsection{Evaluation of enthalpy and free energy of formation of $\mathrm{NiWO}_{4}$}

Since the calorimetric data and free energy measurements of Jacob (1977) are reasonably concordant, an average value for the $\Delta_{\mathrm{f}} H_{\mathrm{m}}^{0}\left(\mathrm{NiWO}_{4}, \mathrm{cr}, 298.15 \mathrm{~K}\right)=$ $(-1126.97 \pm 4) \mathrm{kJ} \mathrm{mol}^{-1}$ may be selected. The free energy of formation can be calculated 


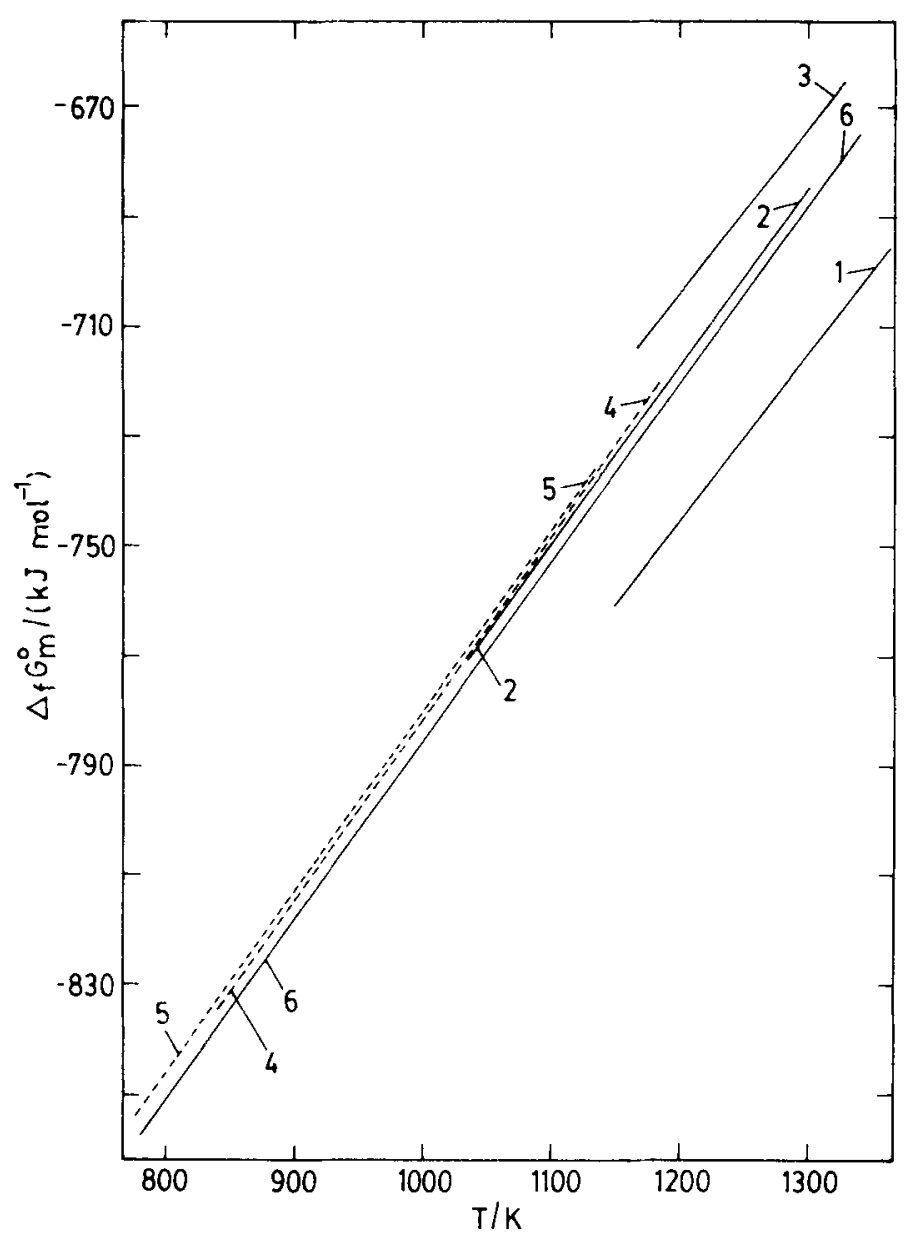

Figure 3. Temperature dependence of the standard molar Gibbs free energy of formation of $\mathrm{NiWO}_{4}$. Data from measurements: (1) Rezukhina and Kashina (1974), (2) Jacob (1977), (3) Aune et al (1994). Data from compilations: (4) Knacke et al (1991), (5) Mah and Pankratz (1976). The results of this evaluation are shown by line 6 .

at regular intervals of temperature based on the $\Delta_{\mathrm{f}} G_{\mathrm{m}}^{0}\left(\mathrm{NiWO}_{4}, \mathrm{cr}, 298 \cdot 15 \mathrm{~K}\right)$ and other thermal functions based on calorimetric data. The computed values for $\Delta_{\mathrm{f}} G_{\mathrm{m}}^{0}\left(\mathrm{NiWO}_{4}, \mathrm{cr}\right)$ are also given in table 1.

The standard free energy of formation from different studies and compilations are compared with the data selected in this study, in figure 3 . The selected data set is in reasonable accord with the values suggested by Jacob (1977) based on the e.m.f. measurements and earlier compilations of Mah and Pankratz (1976) and Knacke et al (1991). The uncertainty in the free energy of formation evaluated in this study is $( \pm 4) \mathrm{kJ} \mathrm{mol}^{-1}$. The free energy data of Rezukhina and Kashina (1974) are significantly more negative. The values of free energy of formation of $\mathrm{NiWO}_{4}$ suggested recently by Aune et al (1994) are on the average more positive than the selected data by $\sim 20 \mathrm{~kJ} \mathrm{~mol}^{-1}$.

Aune et al (1994) calculated the phase diagram for the system (Ni-W-O) based on their data on the free energy of formation of $\mathrm{NiWO}_{4}$. The topology of the computed 
diagram depends critically on the input thermodynamic data. It is clear from the above discussion that the diagram suggested by Aune et al (1994) is not based on the best available information on the free energy of formation of $\mathrm{NiWO}_{4}$. More specifically, their computed phase relations involving the phase $\mathrm{NiWO}_{4}$ would be seriously affected.

\section{Summary}

The selected values of $\Delta_{\mathrm{f}} G_{\mathrm{m}}^{0}\left(\mathrm{NiWO}_{4}, \mathrm{cr}\right)$ at various temperatures are based on the three calorimetric measurements (Porshina and Rezukhina 1960; Navrotsky and Kleppa 1969; Amosse and Mathieu 1974) of the heat of formation of $\mathrm{NiWO}_{4}$ and one set of free energy data (Jacob 1977) which are in reasonable agreement. Two (Rezukhina and Kashina 1974; Aune et al 1994) of the three sets of the reported free energy data are found to be inconsistent with the calorimetric information. In computation of reliable phase diagrams it is important to use the best available thermodynamic information.

\section{List of symbols}

$C_{\mathrm{p}, \mathrm{m}}^{0} \quad$ Standard molar heat capacity.

$T$ Thermodynamic temperature in kelvin.

$\Delta_{\mathrm{f}} G_{\mathrm{m}}^{0} \quad$ Standard molar Gibbs free energy of formation from elements.

$\Delta_{\mathrm{i}} G_{\mathrm{m}}^{0} \quad$ Standard molar Gibbs free energy change for reaction i.

$\Delta_{\mathrm{f}} H_{\mathrm{m}}^{\mathrm{O}} \quad$ Standard molar enthalpy of formation from elements.

cr crystal

GEF Gibbs energy function.

\section{References}

Amosse J and Mathieu J C 1974 C. R. Acad. Sci. Paris C279 871

Aune R E, Sridhar S and Du Sichen 1994 J. Chem. Thermodynamics 26493

Charette G G and Flengas S N 1968 J. Electrochem. Soc. 115796

Jacob K T 1977 J. Mater. Sci. 121647

Jacob K T and Srikanth S 1988 J. Mater. Res. 3687

Knacke O, Kubaschewski O and Hesselmann K 1991 Thermochemical properties of inorganic substances, (Berlin Heidelberg: Springer-V erlag)

Kvernes I and Kofstad P 1973 Scand. J. Metall. 291

Landee C P and Westrum Jr E F 1976 J. Chem. Thermodynamics 8471

Mah A D and Pankratz L B 1976 Contributions to the data on theoretical metallurgy, Bulletin 668, U.S. Department of the Interior, Bureau of Mines, Washington D.C.

Navrotsky A and Kleppa O 1969 J. Inorg. Chem. 8756

Pankratz L B 1982 Thermodynamic properties of elements and oxides, Bulletin 672, U.S. Department of Interior, Bureau of Mines, Washington D.C.

Porshina Z V and Rezukhina T N 1960 Russ. J. Inorg. Chem. 5488

Rezukhina T N and Zharkova L A 1958 Zhur. Fiz. Khim. 322233

Rezukhina T N and Kashina T A 1974 Russ. J. Phys. Chem. 481702

Rizzo F E, Bidwell L R and Frank D F 1969 Trans. Metall. Soc. AIME 2391901 